\title{
Las mujeres como clase social: origen y desarrollo de una teoría. De los Colectivos Feministas al Partido Feminista de España (1975-1983)
}

\author{
Women as a social class: origin and development of a theory. \\ From the Feminist Collectives to the Feminist Party of Spain \\ (1975-1983)
}

\author{
SORAYA GAHETE MuÑoz \\ Instituto de Investigaciones Feministas \\ Universidad Complutense de Madrid
}

Recibido: 30/7/2019

Aceptado: 22/9/2019

doi: https://doi.org/10.20318/femeris.2020.5787

\begin{abstract}
Resumen: El feminismo español de los años setenta y ochenta se inscribió dentro de las tendencias feministas desarrolladas en la llamada segunda ola. Entre estas tendencias podemos señalar el feminismo materialista, es decir, aquel que basándose en los postulados marxistas elaboró su propia teoría sobre el origen de la explotación de las mujeres y desarrolló distintas tácticas para subvertir la realidad. En España, esta tendencia fue representada, en un primer momento, por los llamados Colectivos Homologados del Estado Español y, posteriormente, por el Partido Feminista de España que desarrolló mucho más la idea anunciada por los Colectivos: la mujer como clase social. Al igual que ocurrió a nivel internacional, la formulación de esta idea ocasionó distintos debates entre sus detractoras, especialmente, en aquellas vinculadas al feminismo marxista para quienes la teoría marxista no podía extrapolarse a la situación de las mujeres porque la realidad de estas y de la clase obrera era totalmente distinta. Planteamiento que no compartieron las organizaciones citadas anteriormente y que intentaron demostrar que las mujeres forman una clase social al estar insertas dentro del modo de producción doméstico.

Palabras clave: feminismo español, década de los setenta y ochenta, feminismo materialista, colectivos feministas, Partido Feminista de España.
\end{abstract}

Abstract: The Spanish feminism of the seventies and eighties was part of the feminist tendencies developed in the so-called second wave. Among these trends we can point out materialist feminism, that is, one who, based on Marxist postulates, carried out his own theory about the origin of the exploitation of women and developed different tactics to subvert reality. In Spain, this trend was represented, at first, by the so-called Homologated Collectives of the Spanish State and, later, by the Feminist Party of Spain that developed much more the idea announced by the Collectives: women as a social class. As happened internationally, the formulation of this idea caused different debates among its detractors, especially those related to Marxist feminism for whom Marxist theory could not be extrapolated to the situation of

*sgahete@ucm.es 
women because the reality of these and of the Working class was totally different. Statement that the organizations mentioned above did not share and that tried to show that women form a social class by being inserted into the domestic production mode.

Keywords: Spanish feminism, seventies and eighties, materialist feminism, feminist collectives, Feminist Party of Spain.

\section{Introducción}

El presente artículo tiene como objetivo principal llevar a cabo un análisis de dos de los principales puntos de la teoría desarrollada por el Partido Feminista de España (PFE): las mujeres como clase social y el trabajo doméstico como modo de producción. Dicho análisis se realizará de forma temporal, es decir, se estudiará el surgimiento de esta teoría en España entre las organizaciones feministas que, ya en 1975 empiezan a plantear algunas de estas ideas y cómo las terminó desarrollando el PFE. También se atenderá al contexto internacional viendo qué autoras expresaron algunos de los planteamientos que luego fueron recogidos por estos colectivos y, posteriormente, por el PFE. De esta forma se podrá trazar un eje que permita ver la evolución de este pensamiento en España de acuerdo con criterios temporales, así como de las distintas organizaciones que se adhirieron a él.

El estudio finaliza en 1983 por dos cuestiones fundamentales: en primer lugar, la extensión máxima que se le puede dar a un tipo de trabajo en este formato y, en segundo lugar, porque en 1983 tiene lugar el I Congreso del PFE, donde se exponen de manera conjunta sus principales tesis, algunas de las cuales varían con respecto a las planteadas en 1979 (año en el que se publicaron las tesis del Partido). Por tanto, resulta una buena fecha para cerrar y ver así cómo estos planteamientos surgen en España de una forma más clara a partir de 1975 y van tomando forma hasta 1983, siendo varias las organizaciones feministas que los llevaron a cabo.

Hay que señalar que, aunque se aborden pocos años, las diferencias entre lo acontecido no solo a nivel político sino dentro del movimiento feminista a mediados de los setenta y lo que ocurre en los ochenta varía significativamente. Si bien, el feminismo de los setenta cuenta con una importante bibliografía no ocurre lo mismo con el movimiento feminista en los ochenta. Aunque existe un mayor volumen documental, su estudio resulta más complejo por la división existente dentro del propio movimiento feminista, división que también se dio a mediados de la década de los setenta, pero en la que hubo una mayor cohesión entre las distintas organizaciones feministas con el fin de llevar a cabo distintas campañas. Ni para una década ni para la otra se han reflejado los distintos debates que hubo entre las organizaciones feministas en torno a la idea de las mujeres como clase social, ya que esto llevaría a la realización de otro artículo.

En lo que respecta a las fuentes utilizadas para realizar este trabajo, a parte de las secundarias, han sido, fundamentalmente, diferentes escritos de los Colectivos Feministas y del PFE, que se pueden encontrar en distintos archivos o, bien, en fuentes hemerográficas como Vindicación Feminista y Poder y Libertad, entre las principales. Como se verá a lo largo del texto las aportaciones realizadas por el Colectivo Feminista de Barcelona y Madrid 
serán más señaladas frente a las de otros Colectivos, por el mayor volumen documental que sobre estos dos Colectivos se dispone frente a los otros.

\section{Contexto histórico}

El movimiento feminista español se encuadra dentro de lo que la mayoría de las autoras llaman segunda ola ${ }^{1}$, que presenta una serie de características comunes como: su vinculación a los nuevos partidos de izquierdas, especialmente, en el ámbito anglosajón y norteamericano; su crítica, por lo general, al sistema capitalista e imperialista; se plantea ir más allá de la igualdad entre los sexos para "indagar de manera penetrante en las estructuras de la dominación para entender cómo se construye la subyugación de las mujeres, la construcción de la mujer como «alteridad absoluta»" (Reverte, 2010:19), tal y como ya había establecido Simone de Beauvoir. Un rasgo característico de esta segunda ola del feminismo es la gran diversidad de planteamientos que van a estar presentes y que evidenciarán la multiplicidad de grupos existentes, algunos de ellos con ideas totalmente opuestas.

Una primera división se puede establecer entre las feministas reformistas y las feministas radicales. Para las primeras los objetivos principales eran conseguir la igualdad legal de las mujeres con respecto a los hombres, considerando que así se ponía fin a la discriminación de las mujeres. Por su parte, las feministas radicales, normalmente pertenecientes a sectores universitarios y con contactos con la Nueva Izquierda, aparte de buscar los orígenes de la subordinación femenina, plantearon otros temas como esenciales para la liberación de la mujer. Erradicar la violencia, las agresiones sexuales y la violación se convirtieron en caballo de batalla de muchas organizaciones feministas, que entendían que estas acciones representaban una clara muestra del poder masculino sobre la mujer.

La segunda ola cuestionó el dominio masculino no sólo en la política, la educación y el empleo, sino también en la esfera "privada" de la familia y las relaciones sexuales (Bassnett, 2000: 1119).

Asimismo, se empezó a prestar atención a la raza y a la orientación sexual, como elementos que contribuían a una mayor discriminación de las mujeres. Otra de las diferencias significativas dentro del movimiento feminista la encontramos entre aquellas que intentaron conjugar feminismo y socialismo o feminismo y marxismo, y las que aun utilizando las bases teóricas de la izquierda dieron prioridad al sexo frente a la clase, considerando, por tanto, que es el patriarcado la causa principal de la opresión femenina y no el capitalismo, aunque exista una relación entre ambos sistemas.

\footnotetext{
${ }^{1}$ Desde el ámbito historiográfico es común dividir el movimiento feminista en tres olas: la primera, se correspondería con los movimientos sufragistas y el feminismo socialista (finales del siglo XIX-principios del siglo XX); la segunda ola tendría lugar a partir de los años 60 y 70; y la tercera desde los ochenta. La cronología es aproximada, ya que varía en función de los países. Por su parte, desde la filosofía se hace referencia a la primera ola en el siglo XVIII con el desarrollo del pensamiento ilustrado y la segunda, se correspondería con los movimientos sufragistas y el feminismo socialista; y así sucesivamente. (Amorós, 2005)
} 
En España, el movimiento feminista se vio muy condicionado por el contexto histórico ${ }^{2}$ en el que se desarrolló: una dictadura de casi cuarenta años que, aparte de privar de gran parte de las libertades a la mayoría de la ciudadanía, con respecto a las mujeres las sometió a una legislación que las consideraba prácticamente menores de edad y, por tanto, sometidas a la autoridad de un varón; así como a una propaganda ideológica que las concebía únicamente como madres, esposas y amas de casa. Esta situación no permaneció de forma monolítica durante casi los cuarenta años de dictadura, los cambios son ya apreciables a partir de la década de los sesenta, especialmente entre la población más joven. Esto hizo que las primeras reivindicaciones del movimiento feminista estuviesen centradas en cambios legislativos, algo que no ocurrió en otros países europeos o en EEUU.

Una característica también propia de España fue la división que se dio en las organizaciones feministas entre las partidarias de la doble y la única militancia, dado la necesidad que veían, la mayoría de ellas, de ser partícipes de los cambios políticos que se avecinaban tras la muerte del dictador. En este sentido las "principales tendencias" que se dieron a mediados de los setenta fueron las organizaciones que apostaron por un feminismo socialista o marxista, en el que se dio prioridad a la clase frente al sexo; y aquellas que apostaron por un feminismo de corte materialista, es decir, que aplicaron la teoría marxista a la situación de las mujeres. Por su parte, en la década de los ochenta, nos encontramos con un feminismo que se autodenominó independiente, generalmente, vinculado al feminismo de la diferencia, y un feminismo institucionalizado, como las dos tendencias con mayor fuerza.

Los debates también cambiaron de una década a otra, si a mediados de los setenta las principales reivindicaciones se centraban en: la legalización de los anticonceptivos, el aborto, el divorcio, la despenalización del adulterio, la igualdad ante la ley, la derogación de las leyes que discriminaban a las mujeres, etc.; en la década de los ochenta se seguirán reivindicando ciertos temas como el aborto, todavía no conseguido o a partir de 1985, no conseguido en los términos en los que se pedía. Al tiempo que se acentúan los debates sobre temas relativos a la sexualidad, la identidad de las mujeres o el lesbianismo. De hecho, será en la década de los ochenta cuando se constituyan muchas de las organizaciones de lesbianas, con anterioridad su participación se había dado en las organizaciones feministas o en los colectivos homosexuales.

\section{Breve historia de los Colectivos Feministas y del Partido Feminista de España}

El PFE fue la única organización que en los años setenta se constituyó en un partido político, existieron otros en diferentes países europeos, cuya actividad llega hasta la actualidad. Constituido bajo notario en 1979, no fue legalizado hasta 1981. Sus antecedentes directos los encontramos en los Colectivos Feministas, concretamente en el de Barcelona, uno de los primeros en constituirse. Estos Colectivos que, aunque no muy numerosos en militancia, tuvieron una importante influencia dentro del feminismo español de mediados

\footnotetext{
${ }^{2}$ Así lo explicitan autoras como Mercedes Augustín Puerta, Justa Montero o Paloma Uría Ríos (Ver bibliografía).
} 
de la década de los setenta, ya que entre 1980 y 1981 desaparecen como tal. Fueron organizaciones que defendieron la única militancia, al entender que el feminismo era política, por tanto, según su punto de vista no tenía sentido militar en dos organizaciones. Fueron, a su vez, colectivos que elaboraron una teoría cuya principal idea era que las mujeres forman una clase social y basaron sus postulados en la teoría marxista, por lo que se los encuadra dentro de la corriente del feminismo materialista. No obstante, en el contexto español del momento se los relacionó con el feminismo radical, entendiéndose por feminismo radical como aquel que no se conforma con meras reformas legislativas, sino que plantea un cambio revolucionario, algo que defendieron, efectivamente, los Colectivos.

Estas organizaciones, a pesar de formar los llamados Colectivos Homologados del Estado Español, no constituyeron un grupo homogéneo. De hecho, no se ha encontrado hasta la fecha ningún documento conjunto en el que se estableciese un programa común. De hecho, según las investigaciones realizadas ${ }^{3}$ sobre estas organizaciones no se puede afirmar que mantuvieran una comunicación fluida y solo han transcendido dos reuniones entre ellos. No obstante, leyendo los distintos textos elaborados por estos Colectivos, especialmente los de Madrid y Barcelona, se pueden señalar una serie de puntos en común. Por ejemplo, la idea de que las mujeres constituían una clase social, la familia como principal institución opresora de la mujer, la consideración del trabajo doméstico como un trabajo productivo que constituía a su vez un modo de producción, la toma del poder por parte de las mujeres mediante la creación de un Partido Feminista o la defensa de la única militancia. Hay que señalar, no obstante, que muy pronto algunos Colectivos empezaron a cuestionar algunas de estas ideas.

El PFE proviene de una escisión realizada en el Colectivo Feminista de Barcelona. Esta escisión tuvo su origen en una reunión celebrada en Castellón entre todos los Colectivos los días 8 y 9 de abril de 1977. Sobre lo acontecido en esta reunión que acabó con la expulsión de Lidia Falcón, Regina Bayo y Anna Estany del Colectivo Feminista de Barcelona se tienen dos versiones. La del propio Colectivo de Barcelona que acusaron a estas tres mujeres de actitudes jerárquicas, al boicotear todas aquellas decisiones que no saliesen de ellas, al publicar opiniones que no habían sido discutidas por el Colectivo previamente, al otorgarse la representatividad del Colectivo o al convertir Vindicación Feminista en el vehículo transmisor de los Colectivos, cuando no se había acordado asít . Por su parte, Lidia Falcón argumentó que su expulsión se había debido a motivos meramente personales auspiciados por Paloma Saavedra, del Colectivo Feminista de Madrid 5 . Después de este acontecimiento Lidia Falcón, Regina Bayo y Anna Estany crearon la Organización Feminista Revolucionaria (ORF) que dio lugar posteriormente al PFE.

\footnotetext{
${ }^{3}$ El conocimiento que todavía se tiene de los Colectivos Feministas es escaso. Ma Ángeles Larumbe ha dado en sus dos obras (ver bibliografía) algunos apuntes sobre el Colectivo de Barcelona; Maa del Carmen Suárez aborda tímidamente el Colectivo de Oviedo en su tesis doctoral; del Colectivo de Castellón se han conocido recientemente algunos detalles de cómo funcionaba, gracias a las entrevistas que realizó el grupo ISONOMIA a Ma ángeles López Sierra, a Isabel Sabater y, sobre todo, a Pilar Dolz; y el de Madrid ha sido estudiado en una reciente tesis doctoral. Del resto de Colectivos (Sevilla, Ibiza, Valencia) todavía no se sabe prácticamente nada.

${ }^{4}$ Opción. Revista de la mujer liberada, no 7, junio de 1977.

${ }^{5}$ Escrito de carácter personal, (s.f.), (Documento inédito), Archivo Nacional de Cataluña, Fondo privado de Lidia Falcón, Carpeta del Colectivo Feminista de Barcelona.
} 
Según interpretación de Ma Ángeles Larumbe, los Colectivos, para el PFE, constituyeron una fase de elaboración teórica y la ORF una fase de institucionalización (Larumbe, 2002: 227). Como se ha comentado con anterioridad, el PFE se inscribió bajo notario el 9 de mayo de 1979 aunque no consiguió su legalización hasta 1981. Durante este transcurso temporal realizó distintas actividades, entre las que podemos destacar su intento de participar en las elecciones autonómicas de 1980. Sin embargo, al no haber sido legalizado formó parte de un Frente de Mujeres que llegó a elaborar un programa electoral, el cual fue criticado por otras organizaciones feministas por su carácter moderado ${ }^{6}$. Debido a problemas con la junta electoral no pudieron concurrir a las elecciones, por lo que decidieron apoyar la candidatura política que estuviese dispuesta a defender el programa elaborado por el Frente de Mujeres. Algo que solo fue aceptado por el BEAN-Unitat Popular (Bloc d'Esquerra d'Alliberament nacional) (Larumbe, 2002: 227).

También, en 1980, participó en distintas Jornadas como las Jornadas sobre Patriarcado desarrolladas en la Universidad de Barcelona, las Jornadas para la Mujer en Copenhague, Jornadas sobre sexualidad femenina o las celebradas por ellas mismas en junio de ese mismo año en apoyo a su legalización. Sus principios teóricos no solo fueron expuestos en estas Jornadas sino también a través de numerosos debates en la televisión, radio, etc., así como en las páginas de lo que será su nueva revista Poder y Libertad, cuyo primer número data de 1980. Asimismo, crearon el Club Vindicación Feminista como un lugar de encuentro para las mujeres que funcionaría como: asesoría jurídica, asistencia psicológica, planificación familiar, actividades culturales, etc.

En lo que respecta a su proceso de legalización, y a falta de consultar fuentes primarias, cabe señalar la interpretación que sobre esta cuestión realiza Ma Ángeles Larumbe. Una de las primeras objeciones que le fue realizada en el Registro de Partidos Políticos es en lo que respecta a la no aceptación de hombres en las filas del Partido, algo que atentaba contra uno de los principios de la Constitución. Según, esta autora fue más bien la situación política del momento (el 23 de febrero de 1981 se producía el intento de golpe de Estado del Coronel Tejero) lo que ralentizó la legalización de este Partido hasta marzo de este mismo año.

Sólo el resultado de los últimos acontecimientos y la renuncia explícita de las grandes formaciones de izquierda a ir más lejos permite explicar ese súbito giro dado por la burocracia ministerial (Larumbe, 2002: 269).

El PFE es una organización compleja, con muchos años de historia, 1979 hasta la actualidad, y pendiente todavía de varios estudios que analicen distintos aspectos de este partido $^{7}$ como el liderazgo de Lidia Falcón, la evolución de su pensamiento, sus afiliadas, su deriva política, etc. El objetivo de este trabajo es, por tanto, iniciar la investigación sobre uno de estos puntos: el origen de dos ideas fundamentales en la teoría del PFE: las mujeres como clase social y el trabajo doméstico, entendido como un modo de producción.

${ }^{6}$ Dones en Lluita, no 15, 1979. Recogido en (Larumbe, 2002: 252).

${ }^{7}$ La autora que más ha estudiado a estar organización es Ma Ángeles Larumbe (ver bibliografía). 


\section{Puntos esenciales de la teoría del Partido Feminista de España}

Aunque la idea principal que define al PFE es la mujer como clase social, se desarrollará, en primer lugar, el trabajo doméstico como modo de producción para poder entender posteriormente la afirmación de la mujer como clase social. Asimismo, se abordará otro de los planteamientos defendidos, en un primer momento, por los Colectivos y posteriormente por el PFE, la toma de poder por parte de las mujeres. Hay que señalar, que por la longitud que este trabajo tiene que adquirir no se van a abordar otros aspectos importantes también dentro del pensamiento del PFE, pero compartidos también por el feminismo español (aunque ya, fundamentalmente, en la década de los ochenta) como son aspectos relacionados con la sexualidad, la violencia hacia las mujeres, la prostitución, la pornografía o el lesbianismo.

\section{El trabajo doméstico como modo de producción}

El trabajo doméstico es aquél que realizan todas las mujeres -por el mero hecho de ser mujer- en el núcleo familiar. Es un trabajo útil, puesto que requiere la utilización de materiales, el uso del esfuerzo físico y produce unos bienes de uso necesarios para el mantenimiento de la fuerza de trabajo y tiempo para desarrollarlo (Partido Feminista, 1979: 52).

Sobre la idea del trabajo doméstico como modo de producción se basarán el resto de los planteamientos del PFE y fue, asimismo, lo primero en desarrollarse por parte del resto de Colectivos. Por tanto, aunque lo que definió al PFE y a los Colectivos fue la idea de las mujeres como clase social, para explicar este planteamiento es necesario desarrollar, en mayor medida, el tema del trabajo doméstico. En primer lugar, expondré las características fundamentales para entender por qué consideraron este trabajo como un modo de producción para pasar posteriormente a ver las pequeñas diferencias existentes en esta interpretación entre los Colectivos y el PFE.

Consideraron el trabajo doméstico como una actividad atribuible a todas las mujeres, aunque pronto señalaron las diferencias existentes en función de la clase social a la que perteneciese el marido. Para ellas, el trabajo doméstico tiene las siguientes características: en primer lugar, produce bienes para el autoconsumo familiar, por tanto, produce "valores de uso" y no "valores de cambio", aspecto que lo diferenciaría de otro tipo de trabajos. En segundo lugar, se trataría de un trabajo rutinario y repetitivo que carece de creatividad. En tercer lugar, se le atribuye un carácter natural, realizado por las mujeres. Y, en cuarto lugar, destacan la reproducción de la fuerza de trabajo como aspecto importantísimo y diferente con respecto a otro tipo de trabajos (Partido Feminista, 1979: 54).

Uno de los aspectos en los que podemos encontrar una evolución en este análisis es sobre si el trabajo doméstico produce plusvalía o no. En 1976, el Colectivo Feminista de Barcelona señalaba que este era todavía un aspecto que estaban estudiando, ya que si lo 
veían claro en una familia obrera no les ocurría lo mismo en una familia burguesa ${ }^{8}$. Posteriormente, el PFE negará que el trabajo doméstico produzca plusvalía, aunque sí un trabajo excedente del cual se apropia directamente el marido (Partido Feminista, 1979: 60-61).

Interpretación algo diferente fue la que llevó a cabo el Colectivo Feminista de Madrid. Esta organización procedió, en un primer momento, a cuantificar el trabajo doméstico, asignándole un valor igual que el que recibiría en el mercado. No obstante, pronto se dieron cuenta de la dificultad de este proceso, fundamentalmente, por dos aspectos: el primero, que había actividades que el ama de casa realizaba que no tenían su equivalente en el mercado del momento, por ejemplo, la reproducción. El segundo, que la mujer, al contrario que el trabajador, no recibía un salario real por ese trabajo sino simplemente un sustento que variaba en función del marido. Además, posteriormente, añadieron que las mujeres a lo largo de su vida consumen y producen de forma diferente, es decir, una mujer con hijos/as producirá más que una mujer que no los tenga. Esto les llevó a establecer que una mujer a lo largo de su vida podía pasar de la condición de explotada (cuando producían más de lo que consumían) a oprimida (cuando producían igual o menos de lo que consumían) (Colectivo Feminista de Madrid, 1979: 17-18).

Por ello, centraron su análisis no en la producción de excedente sino en la cuantía que les era otorgada a las mujeres por el trabajo doméstico. Pasaron, por tanto, a abordar esta situación no desde un punto de vista cuantitativo sino cualitativo. De esta forma, pudieron extraer un aspecto común a todas las mujeres (casadas): la dependencia económica de la mujer al marido. De tal forma que llegaron a comparar la situación de las mujeres con la servidumbre e incluso con la esclavitud, ya que el marido se adueñaba del trabajo realizado por la mujer dentro de la familia, no otorgándole a cambio ningún salario, tan solo ofreciéndole una manutención. La familia daría lugar a un modo de producción y se establecerían unas relaciones de producción entre el hombre y la mujer, que estarían "encubiertas por una vinculación de tipo afectivo-erótico-sexual que hace más difícil sacar a la luz su verdadero carácter" (Colectivo Feminista de Madrid, 1978: 6).

Otro aspecto interesante es la distinta interpretación que recibió uno de los temas muy debatidos en el feminismo de estos años, especialmente en el extranjero, y que era la relación entre la situación de la mujer y el capitalismo. En España, en un momento en el que todas las organizaciones que se declarasen revolucionarias tenían que ser anticapitalistas, la mayoría de feministas defendieron que la liberación de la mujer no podría darse dentro del sistema capitalista. Así se manifestó ya en este encuentro de los Colectivos Feministas del año 76, donde, no obstante, la representante del Colectivo Feminista de Barcelona va más allá al plantear si la familia concebida como un modo de producción era fruto sólo del sistema capitalista, ya que "el ama de casa existe en todos los países del mundo, bajo cualquier ideología o sistema político" 9 . Por su parte, el Colectivo de Madrid puso más el foco en el sistema económico como superestructura de la que se derivaría cualquier situación ideológica, religiosa o política.

\footnotetext{
${ }^{8}$ Vindicación Feminista, no3, 1 de septiembre de 1976, p. 15.

${ }^{9}$ Vindicación Feminista, nํㅜ, 1 de septiembre de 1976, p. 15.
} 
Con respecto al PFE se estableció que el modo de producción doméstico estaba dominado y subordinado al sistema capitalista y que era necesario para el desarrollo no solo del capitalismo sino también del socialismo, en tanto en cuanto para ambos sistemas era imprescindible mantener y reproducir la fuerza de trabajo. Es más, argumentaron que tanto el capitalismo como el socialismo, especialmente este último, han embellecido este trabajo para su mantenimiento. Se refieren aquí a las distintas leyes, que especialmente en los sistemas socialistas se han llevado a cabo, que conceden mayores cuotas de igualdad entre el hombre y la mujer en el matrimonio, la introducción de maquinaria que facilita el trabajo doméstico o que cada vez se haga más partícipe al hombre en las actividades del hogar o de la crianza de los hijos. De esta forma, las mujeres se prestarían más servilmente al trabajo doméstico (Partido Feminista, 1979: 56-57). Fue ya en el I Congreso del PFE en 1983, donde se dejó más claro que la familia no era una institución propia del sistema capitalista, ya que esta estaba presente en otros sistemas económicos como el socialismo, por tanto, la superestructura en la cual tenía lugar la familia no era el sistema capitalista o el socialista (aunque, como se ha visto, estos dos sistemas se beneficien), sino otra: el patriarcado ${ }^{10}$.

De hecho, en el I Congreso del Partido plantean la posibilidad de que sea el propio sistema capitalista el que acabe con el trabajo doméstico, ya que según sus análisis fue este sistema el que sacó fuera de la familia algunas actividades productivas, por ejemplo, la fabricación de ropa. Sin embargo, "el ejemplo de los países capitalistas más desarrollados nos obliga a responder negativamente esta pregunta" ${ }^{11}$. Consideran que hay un límite hasta el cual se pueden sacar fuera del ámbito doméstico ciertas actividades productivas, ya que

el Estado capitalista no tiene que establecer una serie de servicios sociales que realicen este trabajo, a un costo mucho más alto que su costo actual, que es irrisorio. De esta forma el capitalismo, al igual que el feudalismo, el socialismo o el esclavismo se beneficia de la explotación de la mujer ${ }^{12}$.

Para ellas el trabajo doméstico es un modo de producción subsidiario que depende del modo de producción dominante, pero establecen que, aunque sea subsidiario no quiere decir que sea residual, ya que no es "un simple vestigio del pasado" o secundario "ya que no tiene una importancia mínima". Es un trabajo tan importante, establecen, que está presente en todos los sistemas económicos.

Con respecto al salario para el ama de casa, una reivindicación muy extendida en otros países como Italia, hay que señalar que, en España, en general, la mayoría de las organizaciones feministas, incluidas los Colectivos, se negaron a ello, ya que consideraban que supondría la perpetuación de esta actividad asignada a las mujeres. Para el PFE un as-

\footnotetext{
${ }^{10}$ Habría que señalar que los Colectivos Feministas en muy pocas ocasiones hablaron de patriarcado como estructura dominante, ya que siguiendo los esquemas marxistas seguían más centradas en encontrar las causas económicas de su explotación.

${ }^{11}$ FREIXAAS, Laura: “El trabajo doméstico”, Poder y Libertad, no 5, julio de 1983, pp. 47-48. En el número 5 de Poder y Libertad se recogen la mayoría de los materiales del I Congreso del PFE, por lo que en la mayoría de los casos se citará esta revista y no la documentación relativa al Congreso, ya que la primera es de más fácil consulta.

${ }^{12}$ Ibidem, p. 49.
} 
pecto positivo de que las mujeres recibiesen un salario por el trabajo que realizan dentro del hogar es que se estaría reconociendo su actividad dentro de la economía capitalista, interpretación que ya fue realizada a su vez por el Colectivo Feminista de Madrid (Gahete, 2017:232). Con respecto al salario del ama de casa, el PFE fue variando su posicionamiento. En 1979 en sus Tesis reconocían que todavía no podían pronunciarse sobre este aspecto al no haber "un estudio serio y profundo de las causas y de los efectos económicos de tal reivindicación". Conocedoras de las tesis de las autoras más destacadas en este tema como María Rosa Dalla Costa o Selma James hacían el siguiente análisis:

El planteamiento político de la lucha económica de la mujer se resume en esta alternativa: o destrucción de la familia como primera estructura económica de explotación femenina, o reformas (una de ellas un salario más alto por el trabajo doméstico) que embellezcan a la familia y hagan más soportable su permanencia en ella a la mujer (Partido Feminista, 1979: 69).

En 1983, consideraban con respecto a lo anteriormente citado que "el trabajo de estos años, la experiencia adquirida en esta andadura nos ha enseñado que no se pueden hacer afirmaciones tan radicales"13. Reclamaron así el salario para el trabajo doméstico como una forma de "darle valor social conscientes de que las mujeres seguirán desempeñando durante mucho tiempo este trabajo"14. De esta forma se posicionaron en la misma línea que el Colectivo Internacional, fundado en el verano de 1972 y formado por mujeres procedentes de Italia, Inglaterra, Francia y Estados Unidos. Partiendo de una perspectiva marxista, entre sus objetivos figuraba también el reconocimiento del trabajo doméstico como un trabajo remunerado (Federici, 2011: 25).

En España, las organizaciones feministas, en general, defendieron la socialización del trabajo doméstico. Esta reivindicación apoyada también por algunos partidos políticos fue criticada por el PFE al considerar que se estaba falseando la realidad. Según su punto de vista, apostar por una socialización del trabajo doméstico supondría dar poder a las mujeres en detrimento de los hombres, aspecto que seguro no llevarían a cabo los partidos políticos ${ }^{15}$. Por el contrario, para algunas organizaciones, entre las que se encuentran los propios Colectivos como el de Madrid,

la socialización del trabajo doméstico, que para el Colectivo constituye la única alternativa posible a la familia, se ha convertido en la actualidad en una reivindicación más dentro del Movimiento Feminista español (Colectivo Feminista de Madrid, 1978: 27).

Uno de los temas más desarrollados por el PFE fue la reproducción. Esta fue considerada en un primer momento (1979) como un modo de producción diferente del modo de producción doméstico ${ }^{16}$. Es más, consideran que la reproducción "es el modo de producción básico sin el cual ningún otro existiría ni hubiera existido nunca. Este modo de

\footnotetext{
${ }^{13}$ ALTARRIBA, Pilar: “Definición del trabajo doméstico”, Poder y Libertad, no 5, pp. 121-122.

${ }^{14}$ Ibidem, p. 123.

${ }^{15}$ FREIXAAS, Laura: “El trabajo..., p. 49

${ }^{16}$ Posteriormente lo entenderán como una actividad que se desarrolla dentro del modo de producción doméstico.
} 
producción es el que en primer lugar define como clase a la mujer" (Partido Feminista, 1979: 41). En este sentido, ya el Colectivo Feminista de Barcelona y posteriormente la OFR establecían en sus bases ideológicas que

la mujer es una clase económica explotada y oprimida por el hombre, en razón de la reproducción de la fuerza de trabajo, como primer modo de producción sustentador de cualquier otro, y del modo de producción doméstico, subsidiario del modo de producción dominante ${ }^{17}$.

Este aspecto las diferenció del Colectivo Feminista de Madrid, por ejemplo, que más cercanas a las tesis de Christine Delphy, defendieron que la reproducción era una actividad más que se desarrollaba dentro del modo de producción doméstico.

El PFE en sus diversos escritos suele abordar el tema del origen de la explotación de la mujer, aspecto que prácticamente no fue abordado por los Colectivos. Se apoyaron para ello en los últimos estudios de antropólogos o sociólogos, y es en la reproducción donde ponen el foco para explicar la histórica subyugación de la mujer al hombre.

Las causas materiales de la explotación femenina se hallan en su propia constitución fisiológica, en su especialización reproductora, en la servidumbre de la gestación, de la parición y del amamantamiento ${ }^{18}$.

Coincidiendo con Engels y sus tesis expuestas, fundamentalmente, en su obra El origen de la familia, la propiedad privada y el Estado, afirmarán que la primera división del trabajo que se realizó fue entre el hombre y la mujer para la procreación de los hijos. El PFE consideró al hijo como un bien, del cual se apropia el hombre. De tal forma que la mujer "produce la fuerza de trabajo, el sirviente y el heredero y el hombre se apropia de todo ello, por el precio de la comida y del techo" (Partido Feminista, 1979: 41-50).

Esto les llevará a defender una medida que fue considerada revolucionaria como fue la abolición de la reproducción, tal y como se solía llevar a cabo, es decir, mediante el mantenimiento de relaciones sexuales entre un hombre y una mujer y el embarazo posterior. Se acercaron aquí a las tesis de Shulamith Firestone, y que más tarde se comentarán. Para ello, defendieron que

la ciencia y la técnica son instrumentos imprescindibles para lograr el desarrollo de la sociedad humana. La ciencia y la técnica son particularmente ventajosas para la mujer porque sólo ellas conseguirán liberarla de las penosas servidumbres de la reproducción ${ }^{19}$.

Otra de las tareas que corresponderían a la mujer dentro de la familia y que formarían igualmente parte del modo de producción doméstico sería la satisfacción de los deseos sexuales del hombre, no obteniendo ella ningún placer. Por tanto: tareas domésticas,

${ }^{17}$ Colectivo Feminista de Barcelona: “Definición del Colectivo Feminista de Barcelona”, 20 de abril de 1977, (documento inédito), Archivo Nacional de Cataluña, Fondo privado de Lidia Falcón, Carpeta del Colectivo Feminista de Barcelona.

18 "La mujer como clase social", I Congreso del PFE, junio de 1983, p. 5.

${ }^{19}$ FALCÓN, Lidia: “Puntos básicos para resolver la crisis económica actual”, Poder y Libertad, no 5, p. 51. 
reproducción y mantenimiento de los hijos junto a la satisfacción sexual del marido serían las actividades que todas las mujeres desempeñarían dentro de la familia y, por las cuales, no recibirían ningún salario, tan solo una manutención. Por ello, el PFE y los Colectivos afirmaron que la mujer está explotada dentro de la familia.

No obstante, no se quedaron solo en el mero análisis teórico, el PFE al ser una organización con más trayectoria temporal, a diferencia de los Colectivos, estableció los "elementos necesarios para la eliminación de la familia" ${ }^{20}$. Esta idea defendida por los Colectivos Feministas fue objeto, no obstante, de crítica por uno de ellos (Colectivo Feminista de Oviedo).

(...) la familia es un sistema de reproducción de la opresión de la mujer y otra cosa es creer que la familia va a destruirse. Amelia es una teórica práctica. Abolir la familia significa que hay que compartir un conjunto de actividades y eso se hacía difícil ${ }^{21}$.

Los planteamientos defendidos por los Colectivos y el PFE no fueron exclusivos de estas organizaciones, sino que muchas de las ideas que desarrollaron ya habían sido formuladas por autoras extranjeras. Tanto fuera como dentro de España hubo una corriente del feminismo que utilizó la teoría marxista como base sobre la cual desarrollar su propia teoría que explicase la histórica opresión de las mujeres y cómo acabar con ella. Estos grupos se enfrentaron dialécticamente a aquellos que consideraban que la teoría marxista no podía extrapolarse al caso concreto de las mujeres.

Entre las feministas, a nivel internacional, que defendieron que la revolución marxista era la base en la que se tendría que sustentar la liberación femenina cabe destacar a Mary-Alice Waters, cuya obra Marxismo y Feminismo (Waters, 1977), fue editada en España en 1977. En ella Waters no analiza los orígenes de la opresión de la mujer, sino que argumenta la necesidad de que el marxismo se convierta en la base de la liberación femenina para que ésta triunfe. Defiende que los teóricos marxistas revolucionarios han sido los únicos que han defendido siempre la liberación de la mujer. Al igual que otras feministas concebirá a la familia como la principal institución que oprime a la mujer, y aunque reconoce que esta institución es anterior a la aparición del capitalismo, defiende que solo a raíz de la aparición de este sistema económico, la familia se convirtió en un sistema opresivo para las mujeres. En la misma línea de Waters se encuentra la obra de Evelyn Reed, Sexo contra sexo o clase contra clase (Reed, 1977), donde a través de una serie de artículos analiza, por un lado, qué factor es el que condiciona a la mujer, el sexo o la clase. Para la autora, la lucha de clases debe ser la primera tarea que solucionar, solo así las mujeres podrán liberarse. Insiste en que no es el hombre el que oprime a la mujer, sino el sistema capitalista y cita ejemplos de países donde el socialismo o comunismo se

\footnotetext{
${ }^{20}$ La abolición de la familia fue una propuesta común en el feminismo, especialmente en el radical, de estos años. En este artículo de Mํㅡㄹ José Ragué lo que se establecen son, fundamentalmente, una serie de alternativas al modelo familiar vigente. Entendiéndose que de esta manera se podría acabar con esta institución. Algunas de las propuestas son: relaciones afectivas libres, placer sexual para la mujer, una reproducción in vitro, la socialización del trabajo doméstico e incluso de los propios hijos, que la familia como tal dejase de contar con una serie de ventajas sociales o políticas, etc. Algunas de estas medidas también fueron propuestas por el Colectivo Feminista de Madrid.RAGUÉ, Ma José: "Elementos necesarios para la eliminación de la familia", Poder y Libertad, no 1, 1980, pp. 67-71.

${ }^{21}$ Entrevista de Mํ del Carmen Suárez a Oliva Blanco Corujo el 21 de enero de 2012 (Suárez, 2012: 524).
} 
han impuesto como China, la URSS o Cuba para afirmar que en esos países la situación de las mujeres ha mejorado. Estos planteamientos fueron muy similares a los presentados por organizaciones como el Movimiento Democrático de Mujeres (MDM) o la Asociación Democrática de la Mujer en España (ADM).

Por su parte, hubo otras teóricas que más cercanas ideológicamente a las tesis de los Colectivos o del PFE, negaron que la implantación de un sistema socialista o comunista fuera a resolver los problemas de las mujeres. Dentro de esta línea se encuentra la autora Zillah Eisenstein, quien en su obra Patriarcado capitalista y feminismo socialista (Eisenstein, 1980), establece la conexión entre patriarcado y capitalismo. Para ella, el patriarcado precede al capitalismo, pero se apoya en éste para establecer la división sexual del trabajo.

Con respecto al trabajo doméstico, un tema que como se ha dicho fue muy importante en los debates teóricos de estos años, distintos estudios analizaron este aspecto; para Margaret Benston, la mujer producía valores de uso y no mercancías (idea también sostenida por el PFE), unos valores de uso por los cuales no recibía dinero, y según la autora "en una sociedad en la que dinero determina el valor, las mujeres constituyen un grupo cuyo trabajo no pertenece a la economía del dinero" (Benston, 1969: 87), de ahí que se derive que el trabajo de la mujer en el hogar en las sociedades capitalistas carezca de valor, idea que también fue sostenida por los Colectivos y el PFE). En lo que coinciden las estudiosas del trabajo doméstico es en que el capitalismo como sistema se sirve de la familia, al convertirse ésta, y gracias al trabajo no pagado de la mujer, en la célula de sustentación de la mano de obra y de reproducción de esta.

Hubo también algunas autoras que, aunque cercanas a estas tesis, consideraron que el trabajo doméstico no era un trabajo productivo, tal y como defendieron los Colectivos y el PFE, exponiendo para ello las diferencias con respecto a un trabajo industrial. Según Wally Seccombe para que el trabajo doméstico pueda ser considerado productivo, éste debe tener dos características: "tiene lugar en relación directa con el capital y produce plusvalía". Para esta autora el trabajo doméstico no se relaciona directamente con el capital porque no es un trabajo asalariado y, por otro lado, no crea más valor del que en sí mismo posee (Harrison, Seccombe y Gardiner, 1975: 64). Dentro de esta línea se encuentra el trabajo de John Harrison para quien el modo de producción capitalista y el modo de producción doméstico son totalmente distintos. El autor compara ambos modos y ve esa diferencia por: 1) El ama de casa frente al obrero es "dueña" de los medios de producción. 2) El ama de casa tiene más "libertad" en la producción, por ejemplo, en cuanto a tiempos de elaboración de un producto o distribución del trabajo. 3) En el trabajo doméstico no hay lo que el autor llama el ciclo reproductivo, es decir, los productos al no venderse no generan un nuevo capital que dará comienzo al nuevo ciclo de trabajo. 4) En el trabajo doméstico no hay intercambio de productos (Harrison, Seccombe y Gardiner, 1975: 15-16)22.

\footnotetext{
${ }^{22}$ Hay un artículo de Laura Freixas publicado en Poder y Libertad en el que la autora también analiza las diferencias existentes entre el trabajo doméstico y un trabajo industrial. Llega a la conclusión de que el trabajo doméstico es un trabajo distinto al que se pueda dar en un sistema capitalista y que esas diferencias son las que hacen que la mujer no esté oprimida por el hombre sino explotada. El trabajo doméstico, por tanto, no sería un trabajo capitalista, pero coexiste con este y el propio sistema se ve beneficiado de dicho trabajo. FREIXAS, LAURA: “El trabajo...".
} 
Asimismo, rechaza la idea de que todas las mujeres formen parte de una misma clase social por el hecho de dedicarse al trabajo doméstico, aunque sí que reconoce que las amas de casa forman una clase distinta a la obrera o burguesa.

Por su parte, Christine Delphy, en cuyos estudios se basó el Colectivo Feminista de Madrid para elaborar su propia teoría sobre la opresión de la mujer, afirmó también la existencia de un modo de producción doméstico, distinto del modo de producción capitalista aunque ambos coexistían. Este modo de producción doméstico sería lo que uniría a todas las mujeres, aunque las prestaciones realizadas variasen en función de la clase social del marido. Según Delphy, todos los maridos se apropiarían del trabajo realizado por la mujer, y esto explica que la mujer no pueda vender en el mercado su trabajo, ya que éste no le pertenece a ella, sino a su marido. Si bien es una idea común de todos los Colectivos, así como del PFE hay que recordar, como más arriba se ha indicado, que el Colectivo de Barcelona y, posteriormente, el PFE desarrollaron en mayor medida el tema de la reproducción hasta considerarlo como el modo de "producción básico", causante inicial de la formación de la clase social mujer. Una de sus propuestas era acabar con la reproducción, tal y como en la época se entendía, como un proceso natural que recae única y exclusivamente en la mujer. Confiaron en que la ciencia algún día consiguiera liberar a las mujeres de este proceso biológico. En esta línea se situó la americana Shulamith Firestone que, aunque encuadrada dentro del feminismo radical, utilizó a su vez conceptos de la teoría marxista para aplicarlos a la situación de las mujeres, para ello sustituyó el término producción por reproducción y clase social por clase sexual (Firestone, 1976).

El objetivo de este apartado no es otro que el de demostrar, aunque su desarrollo haya sido muy somero, que muchos de los debates que se generaron en España sobre cuestiones como: si las mujeres son una clase social, si el trabajo del ama de casa es productivo, puede ser considerado como un modo de producción, produce plusvalía o cómo se relaciona con el sistema capitalista, ya habían tenido lugar en otras partes de Europa o de EEUU. Es más, las feministas españolas tuvieron constancia de estos debates, ya que como se puede ver en la bibliografía estas obras fueron publicadas en castellano unos años después de su publicación original ${ }^{23}$.

\section{La mujer como clase social}

Esta afirmación fue, y sigue siéndolo, una de las ideas más cuestionadas por las distintas organizaciones feministas y cuyo planteamiento parte del apartado anterior sobre el trabajo doméstico. De acuerdo con la teoría marxista, los obreros forman una clase social por el lugar que ocupan en la producción; de tal forma, según los Colectivos y el PFE, las mujeres constituirían a su vez una clase social por el lugar que ocupan en dos modos de producción: la reproducción y el trabajo doméstico (Partido Feminista, 1979: 13-14)24. En

\footnotetext{
${ }^{23}$ También Lidia Falcón en su obra La razón Feminista afirma que la idea de la mujer como clase social ya había sido formulada por otras autoras. (Falcón, 1981: 14).

${ }^{24}$ Como ya se ha indicado más arriba, los Colectivos hablaban de un solo modo de producción: el doméstico; donde la
} 
estos modos de producción la mujer es explotada por el hombre "a nivel sexual, a nivel reproductor y a nivel económico" 25 . Por tanto, el hombre es la clase antagónica de la mujer.

El fin de demostrar que las mujeres constituían una clase social era poder insertarlas en la teoría marxista de la lucha de clases, pudiendo explicar su situación de explotación a lo largo de la historia y diseñar una alternativa de poder. La teoría marxista no había dado respuesta al por qué de la situación de inferioridad de las mujeres a lo largo de la historia y, sobre todo, por qué era una situación que se daba, aunque con diferencias, tanto en las mujeres burguesas como en las mujeres obreras.

Esta interpretación fue, especialmente, cuestionada por organizaciones como el MDM, la ADM e incluso por el Frente de Liberación de la Mujer, para quienes la teoría marxista no podía extrapolarse a la situación de las mujeres o el trabajo doméstico no podía ser considerado productivo en los términos marxistas (Gahete, 2017: 228-230). No obstante, incluso dentro del núcleo original, los Colectivos Feministas, esta idea resultó compleja de asimilar y fue la causante, entre otras cuestiones, de escisiones. Por ejemplo, una de las razones que se dan para explicar la escisión del Colectivo Feminista de Madrid del Seminario Colectivo Feminista también de Madrid es la negativa de una parte de este último grupo de aceptar que las mujeres eran una clase social, tal y como venían defendiendo ya algunos Colectivos, especialmente, el de Barcelona ${ }^{26}$.

Una de las primeras discusiones de las que se tiene constancia entre los Colectivos sobre la idea de la mujer como clase social se dio en una mesa redonda que convocó a los Colectivos Feministas de Barcelona, Sevilla, Castellón, Ibiza y Madrid en 1976. Las discusiones que fueron recogidas en el no 3 de Vindicación Feminista demuestran un nivel de estudio diferente entre los distintos Colectivos, siendo el de Barcelona el que mayores avances estaba realizando a este respecto. No obstante, se observan todavía aspectos no resueltos como la relación existente entre el modo de producción doméstico con el sistema capitalista, si el trabajo doméstico produce plusvalía o no y uno de los ejes de discusión más presentes en el feminismo español de los setenta: las mujeres como sujeto homogéneo ${ }^{27}$. Lo que se observa tanto en el plano teórico como en el práctico es un intento de todas las organizaciones feministas de unir a todas las mujeres bajo una lucha común.

El PFE fue el que desarrolló en mayor medida la idea de las mujeres como clase social. Con respecto a ello, consideraron un error de la teoría marxista el englobar a las mujeres como burguesas o como obreras, ya que el criterio seguido no atendía al lugar que estas ocupan en la producción, sino que se les asigna la clase social a la que pertenece el marido, padre o hermano. De hecho, según el PFE, esto solo ha ralentizado la conciencia de clase de las mujeres a las cuales se les ha convencido "de las diferencias que las separan e incluso las enfrentan según la clase de su marido". Esto ha hecho, como bien expuso Marx, al cual citan, para el caso del proletariado, que las mujeres asuman una conciencia

\footnotetext{
reproducción era una actividad más que el ama de casa realizaba. Interpretación que volverá a ser recogida por el PFE, posteriormente a 1979 cuando se afirmaba que eran dos modos de producción distintos.

${ }^{25}$ SANAHUJA, Ma Encarna: “La mujer como clase social”, Poder y Libertad, no 5, Julio de 1983, p. 54.

${ }^{26}$ Opción. Revista de la mujer liberada, no 7, junio de 1977.

${ }^{27}$ Vindicación Feminista, no, 1 de septiembre de 1976, p. 15.
} 
de clase que no les corresponde y que es la que está en ascenso en ese momento: la clase obrera. "Mientras una clase no tiene fuerza ni conciencia para elaborar su propia ideología, asume la ideología de la clase revolucionaria que le precede, que está en ascenso"28.

No obstante, son conscientes de las diferencias existentes entre las distintas mujeres que, aunque insertas en el modo de producción doméstico, este adquiere características diferentes en función de la clase social del marido. Para referirse a estas diferencias utilizan el concepto de fracción de clase, distinguiendo las siguientes fracciones: mujer burguesa, obrera, campesina, de clase media y soltera, pero todas ellas pertenecientes a una misma clase social ${ }^{29}$.

Por tanto, el factor que convertiría a las mujeres (con sus diferencias) en una misma clase social sería su papel dentro del trabajo doméstico. Para el PFE y algunos Colectivos era necesario que las mujeres asumieran su condición de clase para poder organizarse y luchar conjuntamente por su liberación.

\section{La necesidad de constituirse en un partido político para la toma del poder}

Hubo pocas organizaciones que en los setenta y ochenta se planteasen como uno de sus objetivos inmediatos la toma del poder por parte de las mujeres. A mediados de los setenta, la principal división entre las organizaciones feministas se dio entre las partidarias de la doble y la única militancia, como ya se ha comentado. Aquellas organizaciones (la mayoría en esta década) que defendieron la doble militancia no aspiraban a la toma del poder ellas solas, sino conjuntamente al partido político del que formasen parte. Por su parte, las partidarias de la única militancia, donde cabe destacar a los Colectivos ya tenían entre sus objetivos la toma del poder como el único medio para conseguir la revolución feminista. De hecho, el Colectivo Feminista de Madrid elaboró una serie de fases por las que la toma del poder tendría que pasar para hacerse efectiva (Colectivo Feminista de Madrid, 1978: 34). También, defendieron, como posteriormente lo hará el PFE, el sistema de alianzas con otros grupos oprimidos, pero siempre teniendo en cuenta que la toma de poder por parte de las mujeres no debería ser "excluyente pero sí dominante". Así, lo exponía una militante del Colectivo de Castellón.

Pilar Dolz (Castellón): Como hemos dicho siempre, el feminismo es política, porque como movimiento revolucionario se plantea la subversión total de la sociedad capitalista y machista, donde no sólo se cambie el modo de producción, sino también las relaciones sociales, la ideología y toda la cultura. Consideramos también que debe ser feminismo la toma de conciencia de la mujer de su explotación específica, dentro de la sociedad actual, ligándola y englobándola con el resto de las explotaciones, y la lucha desencadenada como objeto para liberarse, liberando también al resto de la sociedad ${ }^{30}$.

\footnotetext{
${ }^{28}$ SANAHUJA, Ma Encarna: “La mujer...”, p. 60.

${ }^{29}$ Ibidem, p. 64.

${ }^{30}$ Vindicación Feminista, no3, 1 de septiembre de 1976, p. 17.
} 
La revolución feminista sería, por tanto, una revolución que no sólo liberaría a las mujeres, el grupo más numeroso, sino también a otros grupos minoritarios también oprimidos, por ejemplo, los colectivos homosexuales. Para la toma del poder era necesaria la creación de un Partido Feminista, algo ya formulado por Lidia Falcón y Carmen Alcalde en las I Jornadas por la Liberación de la Mujer (1975) (Moreno, 1977: 23). Casi todos los Colectivos compartieron la idea de la necesidad de constituir un Partido Feminista para la toma del poder (Gahete, 2017: 241). Sin embargo, como se ha visto, fue el grupo formado tras la escisión del Colectivo de Barcelona el que finalmente llevó a cabo la constitución del Partido en 1979. Si bien, las críticas en la década de los setenta vendrán, como se ha visto, de las partidarias de la doble militancia hacia la formación de un partido exclusivamente de mujeres; en la década de los ochenta, la principal oposición vendrá de aquellos colectivos que se autodenominaban feministas independientes y que podemos encuadrar, en general, dentro de la corriente del feminismo de la diferencia. Los argumentos dados por estos colectivos sobre la formación de un partido político se basarán, fundamentalmente, en la idea de convertirse precisamente en un partido político, estructura que consideraban machista y que reproducía esquemas como la jerarquía, la división de tareas o la toma de decisiones por una minoría frente a la mayoría. Además, rechazaron muchas de las premisas adoptadas por las distintas organizaciones feministas de los setenta como: el marxismo como la teoría de la liberación de la mujer, la revolución socialista como paso imprescindible para la liberación femenina, el materialismo histórico como único método de análisis de la realidad de la mujer o la toma del poder establecido, por citar algunas (Augustín, 2003: 193).

Por su parte, el PFE se definió y organizó como un partido marxista-leninista ${ }^{31}$ y defendió este tipo de organización frente a las críticas de estos grupos feministas, argumentando que el modelo asambleario (al que se acogieron prácticamente todas las organizaciones feministas, incluidas los Colectivos) también era un modelo masculino y que se había mostrado totalmente inoperante, ponen el ejemplo del movimiento anarquista catalán ${ }^{32}$. Se posicionaron en contra del feminismo de la diferencia, argumentando que

el feminismo es una lucha revolucionaria que no podemos desatender para sumergirnos en ghettos y hablar de utopías: un mundo feminista, con diferente lenguaje y cultura, no organizado y sin jerarquías. La realidad es que si no utilizamos las mismas armas que nuestro enemigo, y no alcanzamos el poder y sólo lo conseguiremos a través de organizaciones estructuradas jerárquicamente, es inútil que nos reunamos durante toda la vida a hablar de ese mundo maravilloso y utópico realizado por mujeres.

(...) y en ningún país del mundo, ni en ninguna época, han conseguido hacer su revolución quienes preconizan la utopía del sistema asambleario. (...) El Partido no puede ser y nunca será un club de amigas y libres teorizantes, ni en él se permiten "tertulias" 33 .

\footnotetext{
${ }^{31}$ En 1983 rechazan ya el calificativo de leninista, al entender que este término ya no encaja en la sociedad del momento. Se unen así a la táctica llevada a cabo por otros partidos de izquierda.

${ }^{32}$ FERNÁNDEZ GARRIDO, Montserrat: "La necesidad de la organización interna y de la jerarquía", Poder y Libertad, no 1 , junio de 1980, p. 31.

${ }^{33}$ Ibidem, pp. 32-33.
} 
Un tema muy presente en el PFE fue, como ya se ha mencionado, la necesidad de que las mujeres adquiriesen conciencia de clase para que la revolución feminista pudiese triunfar. Es más, frente a las críticas que recibieron de otros sectores del feminismo sobre que reivindicaciones como el divorcio, el aborto o la defensa de un salario para el ama de casa no eran medidas revolucionarias, argumentaron que si bien, efectivamente, no lo eran, constituían "la base para la movilización de las mujeres. Permiten su toma de conciencia y su comprensión de los objetivos revolucionarios"34. Por ello, defendieron su participación en la política como la mejor manera de conseguir sus reivindicaciones a corto plazo para después poder llevar a cabo la verdadera revolución.

Una de las cuestiones, por tanto, que más preocupaba al PFE era la escasa e incluso nula conciencia de clase de las mujeres. Esto fue entendido por la alienación que las mujeres sufrían en la que no sólo intervenían aspectos económicos sino también otros como el amor y los sentimientos, mucho más difíciles de desenmascarar, ya que estaban teñidos de un naturalismo impuesto por la ideología dominante durante siglos ${ }^{35}$.

\section{Conclusiones}

En este artículo se ha realizado una breve exposición de dos de las ideas principales de la teoría del PFE: las mujeres como clase social y el trabajo doméstico como modo de producción. Asimismo, se ha abordado de forma sucinta la estrategia a seguir para conseguir la liberación de las mujeres y que se basa/ba, fundamentalmente, en la creación de un partido feminista. De la misma manera, se ha visto qué organizaciones feministas ya defendían algunos de estos planteamientos y como otros fueron modificándose a lo largo del tiempo o en función de cada organización. También se ha atendido, aunque de manera somera al contexto internacional como una forma de demostrar que los debates mantenidos en España ya se habían dado o se estaban dando fuera de las fronteras españolas. De esta forma, se puede afirmar que, si bien el PFE desarrolló en mayor medida las ideas que más arriba se han expuesto, éstas ya fueron formuladas por otras organizaciones feministas en España, pero a su vez tienen una base en otras teóricas extranjeras.

Asimismo, y sin restar la gran importancia que la figura de Lidia Falcón tuvo en el feminismo español y, concretamente, en la formación del PFE, así como en el desarrollo teórico de muchas de las ideas recogidas en este trabajo, habría que matizar que no se la puede considerar como la única ideóloga, tal y como Maa Ángeles Larumbe parece apuntar ${ }^{36}$. Habría que señalar que los Colectivos Feministas que surgieron en distintos puntos de la geografía

\footnotetext{
${ }^{34}$ SANAHUJA YLL, Ma Encarna: “Estrategia y táctica del Partido Feminista”, Poder y Libertad, no 1, junio de 1980, p. 38.

${ }^{35}$ RAGUÉ ARIAS, Ma José: "Identidad de un partido feminista en referencia a otros partidos políticos y organizaciones feministas", Poder y Libertad, no 2, 1981, p. 49.

${ }^{36}$ Este planteamiento de focalizar en la figura de Lidia Falcón casi todo lo relativo a los Colectivos y a su pensamiento prima en la obra de esta autora. Por ejemplo, sin citar ningún tipo de documentación, más allá de una entrevista realizada a la misma Lidia Falcón, da por hecho que fue ella "la principal impulsora" del Colectivo Feminista de Barcelona. Sin embargo, en un documento encontrado en el Archivo de Barcelona, en el Fondo de Lidia Falcón, se establece que el Colectivo Feminista de Barcelona venía funcionando con anterioridad a su presentación oficial en las I Jornadas de Liberación (1975), y que Lidia Falcón se incorporó al Colectivo con posterioridad a su creación. (Larumbe, 2002: 213-214).
} 
española no eran un grupo monolítico, es más para formar parte de una misma estructura (Colectivos Homologados del Estado Español) los contactos entre ellos, como se ha dicho, no fueron muy frecuentes. Cada Colectivo, como se ha visto, aunque compartió una serie de rasgos comunes, formuló una serie de planteamientos diferentes a los que luego hizo el PFE.

La teoría de los Colectivos y del PFE, aunque con sus diferencias, tienen un objetivo común: formular una interpretación que permita explicar de manera "científica" las causas de la opresión de todas las mujeres a lo largo de la historia, pero también establecer una serie de mecanismos que permitan subvertir esta realidad. Se pretendía unir a todas las mujeres, independientemente, de su clase social, su raza, su orientación sexual, edad, etc., en una causa común: la lucha por su liberación, y contra un enemigo común: los hombres. Esto resulta importante debido a la propia división con la que el movimiento feminista ya nace, y que se hace patente en las I Jornadas de Liberación de la Mujer en 1975, y que se terminó de evidenciar en las de Granada de 1979, donde las diferencias y otra serie de circunstancias como los cambios políticos acontecidos hasta la fecha y los logros y fracasos conseguidos, hacen que pese más lo que diferencia a las mujeres que lo que las une.

A mediados de la década de los setenta, los planteamientos introducidos en los debates feministas por los Colectivos, en especial, como se ha dicho, las mujeres como clase social supusieron un auténtico reto debido, por un lado, al menor desarrollo teórico que otras organizaciones feministas van a tener en estos años, y, por otro lado, debido a que estratégicamente esta posición dividía a las mujeres entre las defensoras de la única y la doble militancia, precisamente, en un momento de gran agitación política. A partir de los ochenta, estos planteamientos recogidos ahora por el PFE ya no resultarán tan novedosos y se enfrentan a los introducidos por otras organizaciones feministas, vinculadas muchas de ellas al feminismo de la diferencia y que se oponen no solo a las ideas del PFE sino a su estrategia política a seguir.

Para finalizar, sería interesante señalar como estas ideas que empiezan poco a poco a ser formuladas en España en 1975 tienen su continuidad hasta la fecha actual, año 2019. Es indudable que el discurso ha tenido que ser modificado, aunque en su esencia sigue siendo el mismo, para adaptarse a los grandes cambios que se han producido a lo largo de estas décadas no solo política y socialmente sino también dentro del movimiento feminista, donde van surgiendo nuevas teorías para enfrentarse a los viejos y nuevos retos.

\section{Fuentes primarias y bibliografía}

\section{Fuentes primarias}

Archivos

- Archivo Linz de la Transición española

- Archivo Nacional de Catalunya

- Archivo privado del Colectivo Feminista de Madrid 
- Biblioteca de Mujeres

- Centro de Documentación del Instituto de la Mujer.

Textos

- Colectivo Feminista de Madrid: Puntualizaciones en torno al feminismo radical, febrero de 1978.

- Colectivo Feminista de Madrid: Feminismo y materialismo, noviembre de 1979.

- I Congreso del Partido Feminista de España, 2 y 3 de Junio de 1983.

- I Jornadas Nacionales por la Liberación de la Mujer. Conclusiones. Madrid, 1976.

- II Jornadas Estatales de la Mujer en Granada, 7-9 de diciembre de 1979. Documento on-line, disponible en: http://cdd.emakumeak.org/recursos/2308

- Jornades Catalanes de la Dona. Barcelona, Documentaciones y Publicaciones Generales, S.A, 1977.

- Partido Feminista. Tesis. Barcelona, Ediciones de Feminismo, 1979.

Revistas

- Poder y Libertad, no 1 (1980), no 6 (1985).

- Opción. Revista de la mujer liberada, no 1 (diciembre de 1976), no 7 (junio de 1977).

- Vindicación Feminista, 1976-1979 (mensual)

Fuentes secundarias

ABRIL, María Victoria y MIRANDA, Jesús: La liberación posible. Madrid: AKAL, 1978.

AMORÓS, Celia y DE MIGUEL, Ana (eds.) (2005): Teoría feminista: de la Ilustración a la globalización. 3 vols., vols. I, II y III. Madrid: Minerva, 2010.

ARRIERO RANZ, Francisco: El Movimiento Democrático de Mujeres. De la lucha contra Franco al feminismo. Madrid: Los Libros de la Catarata, 2016.

ASOCIACIÓN "MUJERES EN LA TRANSICIÓN DEMOCRÁTICA": Españolas en la Transición. De excluidas a protagonistas (1973-1982). Madrid: Biblioteca Nueva, 1999.

AUGUSTÍN PUERTA, Mercedes: Feminismo: identidad personal y lucha colectiva. (Análisis del movimiento feminista español en los años 1975 a 1985). Granada: Feminae, 2003.

BALLETBÒ, Ana, CAPMANY, Maria Aurèlia y otras (1972): La liberación de la mujer. Año cero. Barcelona: Granica Editor, 1977. Primera edición en Buenos Aires.

BENSTON, Margaret (1969): “La economía política de la liberación de la mujer”, en RAGUÉ ARIAS, Ma José: Hablan las women's lib. Barcelona: Kairós, 1972.

DELPHY, Christine (1982): Por un feminismo materialista. El enemigo principal y otros textos. Barcelona: Cuadernos inacabados, 1985.

EISENSTEIN, Zillah R. (ed.) (1978): Patriarcado capitalista y feminismo socialista. México: Siglo XXI, 1980. 
ELEJABEITIA, Carmen: Liberalismo, marxismo y feminismo. Barcelona: ANTHROPOS, 1987. ESCARIO, Pilar; ALBERDI, Inés; LÓPEZ-ACCOTTO, Ana Inés: Lo personal es político. El Movimiento Feminista en la transición. Madrid: Instituto de la Mujer, 1996.

FALCÓN O’NEILL, Lidia (1969): Mujer y Sociedad. Madrid: Vindicación Feminista, 1996.

FALCÓN O’NEILL, Lidia: La razón feminista I. La mujer como clase social y económica. El modo de producción doméstico. Barcelona: Fontanella, 1981.

FALCÓN O’NEILL, Lidia: Memorias políticas (1959-1999). Barcelona: Planeta, 1999.

FEDERICI, Silvia: Revolución en punto cero. Trabajo doméstico, reproducción y luchas feministas. Madrid: Traficantes de Sueños, 2011.

FIRESTONE, Shulamith (1970): La dialéctica del sexo. Barcelona: Kairós, 1976.

GAHETE MUÑOZ, Soraya: Por un feminismo radical y marxista. El Colectivo Feminista de Madrid en el contexto de la Transición española (1975-1980). Tesis doctoral dirigida por Gloria Nielfa Cristóbal, junio de 2017. eprints.ucm.es/48188/1/T40067.pdf

HARRISON, John; SECCOMBE, Wally y GARDINER, Jean: El ama de casa bajo el capitalismo. Barcelona: Anagrama, 1975.

LARUMBE, María Ángeles: Minorías activas y feminismo: Aproximación al estudio de los orígenes del Partido Feminista de España hasta su legalización (1975-1981). Tesis doctoral dirigida por Lidia Falcón, Universidad de Zaragoza, 2000.

LARUMBE, María Ángeles: Una inmensa minoría. Influencia y feminismo en la Transición. Zaragoza: Prensas Universitarias de Zaragoza, 2002.

LARUMBE, María Ángeles: Las que dijeron no: Palabra y acción del feminismo en la Transición. Zaragoza: Prensas Universitarias de Zaragoza, 2004.

KRAMARAE, Cheris y SPENDER, Dale (eds.): Enciclopedia Internacional de las Mujeres. Madrid: Síntesis, 5 vols., vol. III, 2000.

MARTÍNEZ TEN, Carmen; GUTIÉRREZ LÓPEZ, Purificación y GONZÁLEZ RUIZ, Pilar (eds.): El Movimiento Feminista en España en los años 70. Madrid: Cátedra, 2009.

MONTERO, Justa: "Movimiento feminista: una trayectoria singular", en EGIDO, Ángeles y FERNÁNDEZ ASPERILLA, Ana (eds.): Ciudadanas, militantes y feministas. Mujer y compromiso político en el siglo XX. Madrid: Eneida, 2011, pp. 231-248.

MORENO, Amparo: Mujeres en lucha. El movimiento feminista en España. Barcelona: Anagrama, 1977.

MORENO SECO, Mónica: Manifiestos feministas. Antología de textos del movimiento feminista español (1965-1985). Alicante: Centro d'Estudis sobre la Dona, Universidad de Alicante, 2005.

NASH, Mary: Dones en Transició. De la resistència política a la legitimitat feminista: les dones en la Barcelona de la Transició. Barcelona: Ajuntament de Barcelona, 2007.

REED, Evelyn (1969): Sexo contra sexo o clase contra clase. Barcelona: Fontamara, 1977.

REVERTE BAÑóN, Sonia: "El feminismo: más allá de un dilema ajeno", Feminismo/s, no 15, 2010, pp. 15-32.

SUÁREZ SUÁREZ, Ma del Carmen: Feministas en la transición asturiana (1975-1983). La Asociación Feminista de Asturias. Oviedo: KRK, 2003. 
SUÁREZ SUÁREZ, Ma del Carmen: El feminismo asturiano en la oposición al Franquismo y en la Transición democrática. Vivencias, conciencia y acción política. Tesis doctoral defendida en la Universidad de Oviedo, 2012.

URÍA RÍOS, Paloma: El feminismo que no llegó al poder. Trayectoria de un feminismo crítico. Madrid: TALASA, 2009.

WATERS, Mary-Alice: Marxismo y Feminismo. Barcelona: Fontamara, 1977. 